\title{
Aprendizagem de pesquisadores científicos com agricultores: reflexões sobre uma prática em Sumidouro (RJ), Brasil
}

\section{Apprenticeship of scientific researchers with farmers: considerations on an educative practice in Sumidouro (RJ), Brazil}

\author{
Eduardo Navarro STOTZ
}

Magali Gonçalves Muniz BARRETO

Marisa da Silveira SOARES

\section{$P^{2}+2=2-2=$ RESUMO}

Este artigo apresenta e discute os significados do aprendizado de pesquisadores dos campos científicos da Biologia e da Sociologia, com agricultores familiares do município de Sumidouro (RJ), a respeito da importância do trabalho educativo no controle da esquistossomose. A intervenção dos pesquisadores propiciou um aprendizado social entre eles e a comunidade de referência, uma vez que, a partir dos laços de confiança construídos, os mesmos passaram a ser vistos como aliados capazes de projetar determinados interesses. A construção destes laços decorreu, no que diz respeito aos pesquisadores, da percepção e da tentativa de superação das dificuldades surgidas no desenvolvimento do trabalho educativo.

Palavras-chave: comunidades ampliadas de pares, educação dos educadores, saúde e ambiente

\begin{abstract}
This article presents and discusses the apprenticeship of Biology and Sociology scientific researchers with farmers from the county of Sumidouro (RJ) in relation to the importance of the educative work in the schistosomosis control. The researchers' intervention provided a social apprenticeship between them and the reference community, once based on the ties of confidence established, they started being seen as friends capable of projecting some interests. The establishment of these ties was a result, in relation to the researchers, of the perception and attempt to overcome difficulties emerged in the development of the educative work.
\end{abstract}


Index Terms: educators' education, popular education, schistosomosis control,

\section{Introdução}

Ao realizarmos nossos primeiros estudos de campo sobre a esquistossomose, na primeira metade dos anos 90, éramos um grupo de trabalho formado exclusivamente por biólogos, que tinha por motivação não apenas a possibilidade de adquirir mais conhecimentos científicos em Parasitologia, Imunologia, Ecologia, dentre outros campos do conhecimento, mas, também, a possibilidade de interagir (e de contribuir) com a natureza e com as pessoas, ou seja, com a "vida real", fora dos laboratórios.

A perspectiva que adotávamos, então, inseria-se na proposta de organizar comunidades ampliadas de pares, para lidar, nos municípios, com a complexidade de situações advindas de diferentes usos da água (SOARES et al, 1998).

Dentre as possibilidades de interação e de contribuição, percebíamos que, em algum momento do trabalho, precisaríamos realizar alguma forma de trabalho educativo, embora não nos reconhecêssemos como educadores. Sentíamo-nos na obrigação de "dar um retorno" à população.

Já nos primeiros contatos com as comunidades humanas, no município fluminense de Sumidouro, em 1995, percebemos que as pessoas tinham conhecimentos apenas fragmentários a respeito da doença, misturando informações "falsas" (segundo a nossa visão) com informações "verdadeiras" (também segundo a nossa visão). Eram pessimistas em relação a soluções de problemas gerais e, em particular, em relação a problemas de saúde. A partir desta percepção, decidimos realizar atividades educativas que pudessem, de acordo com a nossa perspectiva e naquela 
época, ajudá-las a entender a esquistossomose "da forma correta", de modo a poder evitá-la. Pretendíamos, também, sensibilizá-los, para que participassem dos procedimentos de diagnóstico e do tratamento que a equipe oferecia. Neste momento, começamos a assumir o papel de educadores, embora sem referenciais teóricos claros.

Com o passar do tempo, fomos nos dando conta do quanto aprendíamos com cada experiência, e do tanto que o nosso olhar sobre o trabalho se modificava. A partir daí, sem abandonar os objetivos originais, passamos a buscar cada vez mais a nossa própria sensibilização e informação, até que, em um dado momento, percebemos que a nossa visão sobre educação já não era a mesma.

A decisão de sistematizar estas experiências decorreu da oportunidade de participar do V Colóquio Internacional Paulo Freire (SOARES; STOTZ; BARRETO, 2005), embora a motivação tivesse a ver com as dificuldades sociais e políticas para organizar, a partir do trabalho local, a proposta da comunidade ampliada de pares, em Sumidouro.

Seguimos o raciocínio de Roberto Cardoso de Oliveira, o de que os cientistas se pensam no interior de uma 'representação coletiva' (OLIVEIRA, 2000) sobre o papel dos mesmos na sociedade ao definir a educação como eixo da sistematização do trabalho realizado neste município, no período compreendido entre 1995 e 2004.

Para dar conta do objetivo de apresentar o processo de aprendizagem pelos pesquisadores, sistematizou-se este aprendizado ao longo de diferentes momentos ou fases distintas, expressão das direções tomadas pelo projeto pedagógico que acompanhou a intervenção sanitária, a saber: 1) estudo de morbidade referida (1995-96); 2) intervenções educativas (1996-97); 3) 
avaliação do trabalho (1999-2000); e 4) intervenções educativas ampliadas (2003-2004).

Refletir sobre o que se fez, ou se deixou de fazer, muito tempo depois de concluído o trabalho de campo, somente foi possível graças à memória, esse elemento mais rico na escrita de um texto que presentifica o passado (OLIVEIRA, 2000). Certamente os registros escritos e visuais das atividades foram fundamentais para esta presentificação do passado. A rememoração é, contudo, uma classificação e ordenação dos dados que procede a uma reconstrução do passado, conforme os procedimentos sociológicos de distanciamento (BOURDIEU; CHAMBERON; PASSERON, 1999). Neste sentido, procuramos exercitar o distanciamento, na análise dos dados e informações, ao contextualizar a nossa intervenção como pesquisadores vinculados ao setor público e a uma tradição técnica de controle de doenças endêmicas no Brasil; e ao combater sistematicamente a ilusão de transparência da realidade local, construída por conta do compartilhamento do senso comum, oferecido nos processos comunicativos espontâneos.

Decidimos produzir este relato sobre tais experiências, acreditando que este possa ser útil a grupos que não se reconhecem como uma equipe de educadores, embora lidem diretamente com comunidades rurais, em trabalhos sobre saúde e ambiente. Nele, apresentamos um pouco do que aprendemos, na qualidade de pesquisadores de uma instituição científica, com os agricultores familiares que constituem a base da população de um município pobre, como tantos outros municípios brasileiros. 


\section{A esquistossomose em Sumidouro e a nossa equipe de trabalho}

Sumidouro é um pequeno município (14.168 habitantes, no ano de 2000), situado entre a região serrana e o Vale do Paraíba, no estado do Rio de Janeiro. Tem a singularidade de ser o município com menor taxa de urbanização do Rio de Janeiro (85\% da população na zona rural, naquela data). Só é possível, contudo, entender a situação local da esquistossomose ao levar-se em conta certas dimensões de natureza sócio-ambiental: o município tem uma área de 395 quilômetros quadrados, com variações de 264 metros a 1.300 metros; esta variação propiciou a diversificação tanto das atividades agropecuárias como, também, da distribuição do molusco hospedeiro intermediário da esquistossomose. Assim é que, nas "terras quentes", zona mais baixa do município, predominam a pecuária e a agricultura, com baixa produtividade, e concentram-se a parcela mais pobre da população, a falta de saneamento e as áreas com esquistossomose; nas "terras frias", que são mais prósperas, predomina a lavoura com maior produtividade, as condições sanitárias são melhores e são mais raros os moluscos hospedeiros intermediários. A distribuição das atividades econômicas segue um padrão histórico que remonta à superação da crise da cultura cafeeira, em meados do século XX.

Do ponto de vista da investigação, das medidas de controle e de tratamento dos indivíduos com esquistossomose, o município é um dos locais brasileiros que mais tem sido foco de ações. A história local da pesquisa sobre esta endemia remonta ao Instituto Nacional de Endemias Rurais e ao Departamento Nacional de Endemias Rurais, nos anos iniciais da década de 1960. Desde a década de 1970, a Fiocruz tem atuado em pesquisas sobre a esquistossomose no município, através de dois dos seus 
pesquisadores eméritos, o Dr. Luis Fernando Ferreira e o Dr. Luis Rey, cuja equipe lá chegou, no final dos anos 80, e lá trabalha até os dias atuais.

Em colaboração com a equipe do Dr. Rey, com apoio da Prefeitura Municipal e dos agentes locais da Superintendência de Campanhas de Saúde Pública (Sucam), a nossa equipe iniciou suas atividades, no município, em maio de 1995, assumindo os estudos de Epidemiologia e Controle da Esquistossomose em três localidades rurais (Porteira Verde, Pamparrão e Santa Cecília) e em uma localidade peri-urbana (Pedreira), todas situadas na região conhecida como "terra quente". Apesar de os membros mais antigos na equipe sermos biólogos lidando estritamente com questões dessa natureza, concernentes à Biologia e à Medicina, hoje atuamos em projetos interdisciplinares na interface Saúde-Ambiente. No decorrer dessas experiências, a equipe recebeu como reforços as idéias e a participação ativa de jovens biólogos e antropólogos, alguns dos quais lecionavam em escolas públicas ou privadas, no Ensino Fundamental e no Ensino Médio. Como última e fundamental contribuição, um sociólogo, com atuação no movimento de Educação Popular em Saúde, associou-se ao grupo.

\section{Referenciais das experiências do grupo em Educação}

As nossas experiências no campo da Educação, sobretudo as iniciais, originaram-se e foram conduzidas com o auxílio de concepções que não se encontravam no plano científico. Eram, antes, preocupações concernentes à Ética, forjadas pelo senso comum. O que a equipe julgava importante era a atenção (ou o empenho) em prover os pacientes com informações que os auxiliassem a se prevenir e os incentivassem a buscar diagnóstico e tratamento. Havia o respeito às pessoas, acima de tudo. No decorrer do tempo, tais preocupações passaram a ser expressas com outras de natureza metodológica, tais como a necessidade de avaliar as experiências por 
questionários pós-tratamento. Finalmente, o grupo passou a se preocupar com a adoção de métodos quantitativos e qualitativos que conferissem validade científica às experiências educativas.

Sendo coerentes com o propósito, que sempre tivemos, de buscar metodologias educativas que atendessem necessidades da população, intuitivamente, caminhamos no sentido de aprender a ouvir. Assim, de indagações preliminares realizadas com o auxílio de questionários, partimos para a realização de entrevistas, grupos focais, avaliação do nosso trabalho pelas comunidades e tentativas de uma organizar uma Comunidade Ampliada de Pares (FUNTOWICZ; RAVETZ, 1997). Paulatinamente, as próprias transformações das nossas visões constituíam resultados a estimular a busca de novos procedimentos.

\section{Apresentação do processo de aprendizagem pelos pesquisadores}

\subsection{A fase da descoberta: aprendendo a ouvir}

O trabalho de pesquisa, apoiado pela prefeitura municipal, tomou forma nos primeiros contatos com os moradores. A sistemática era a seguinte: o pesquisador apresentava-se como um funcionário da Fiocruz que estava ali para realizar um trabalho de pesquisa voltado para a melhoria da saúde da população; solicitava a colaboração para responder a um questionário; seguia-se a entrega de frascos e recolhimento de amostras de fezes; a entrega dos resultados, o acompanhamento do exame clínico e o tratamento dos doentes concluíam o trabalho.

Algumas das perguntas destinavam-se a identificar o morador e a dispor de alguns indicadores sócio-econômicos (número de cômodos da casa) e sanitários (fonte e canalização de água e esgoto) de sua situação. Eram, portanto, parte de um cadastramento da população. Para saber o que a 
população do local sabia e não sabia sobre o ciclo, a prevenção e o tratamento da doença, na falta de um outro método disponível, adotou-se o procedimento habitual - o do estudo da morbidade referida, com a aplicação de um questionário a 109 responsáveis pelo domicílio (geralmente mulheres).

Estes primeiros contatos - que também serviram para descobrir a configuração sócio-espacial, as diferenças entre as diversas famílias e orientaram a interiorização da pesquisa - propiciaram o entendimento de que os moradores tinham conhecimentos fragmentários sobre a esquistossomose ou a desconheciam. Além disto, simultaneamente, o trabalho "principal" da equipe mostrava que, em alguns grupos populacionais da área, tais como o grupo de homens adultos, o percentual de participação nos exames de fezes poderia ser aumentado. Então, a equipe de pesquisa resolveu ser necessário aumentar o nível de informação da população, influenciar mudanças de atitude, visando à prevenção da transmissão da esquistossomose e ao aumento da participação no diagnóstico e no tratamento da doença.

A maioria (95\%) declarou ter ouvido falar de "caramujo", "barriga d'água" ou esquistossomose, tendo obtido esta informação devido à ocorrência de casos na família e na vizinhança, diagnosticados e tratados pelas instituições estatais de controle da doença, como a Fiocruz. É importante observar que se pretendia saber se a população tinha consciência sobre o problema da esquistossomose, por meio de uma pergunta bastante ampla. Não por acaso, apenas $18 \%$ especificaram a esquistossomose como um problema de saúde, enquanto os demais a registravam em decorrência da própria intervenção de autoridades sanitárias.

A baixa prevalência da esquistossomose na população do município (4\%) não chegava a ser contrastada pela alta prevalência na área de pesquisa 
- que alcançava $20 \%$ em certos grupos - provavelmente porque, devido à precariedade dos serviços de saúde, esses casos não eram conhecidos.

Uma possível hipótese explicativa para a pouca relevância dada à esquistossomose como problema de saúde deveria partir do fato de não existirem casos clínicos graves identificados pela população, o que corresponderia a uma cultura somática de naturalizar as dores abdominais, a ocorrência de melena e de alternância entre prisão de ventre e diarréia, como incômodos e não como sinais de problema de saúde (BERLINGUER, 1988).

Por outro lado, a existência do problema da esquistossomose está associada à intervenção sanitária. Para o bem e para o mal, como se costuma dizer. Assim, a reivindicação, formulada por oito pessoas, da canalização do esgoto doméstico para o rio deixa de ser surpreendente, se considerarmos a característica da intervenção da Sucam (depois Fundação Nacional de Saúde (Funasa)), como relataram dois agentes de saúde que participaram, por mais de 30 anos, a partir de 1960, de ações de controle da esquistossomose no município (SILVA, 2004).

Assim como se constatou, pelas respostas ao questionário, que a maioria sabia da doença pela intervenção das autoridades sanitárias, este trabalho de história oral mostrou que a própria denominação da doença é atribuída a esta intervenção, num contexto de casos graves e reações adversas ao medicamento.

As percepções mais importantes durante esta etapa, geradas por conversas informais com a população e confirmadas pelos depoimentos dos agentes de saúde, dizem respeito ao extremo pessimismo das pessoas, alimentado por experiências passadas mal sucedidas (reações a medicamentos, destruição de lavouras por moluscicidas, fossas 
inadequadas). Ao final desta etapa, estávamos certos de que era necessário "aprender a ouvir para poder intervir".

Em síntese, já nesta etapa do trabalho, percebemos que qualquer intervenção, em educação, demandaria da equipe uma maior compreensão dos anseios, das dúvidas, das curiosidades e das necessidades da população local, principalmente em relação à esquistossomose.

\subsection{Exposição sobre esquistossomose como intervenção educativa}

Em 1996, a equipe resolveu exibir o vídeo "Doença do Caramujo", de Brani Rozemberg, na expectativa de que este material pudesse atender ao objetivo de estimular a prevenção, o diagnóstico e o tratamento da esquistossomose. $\mathrm{O}$ vídeo foi exibido em 10 reuniões na localidade de Porteira Verde. O manual de apresentação e debate do vídeo com as comunidades foram considerados uma verdadeira "camisa de força" na medida em que, pretendendo atingir um compromisso entre técnicos e população, deparava-se com a situação de silêncio - entendido como um sinal de constrangimento ou de desconforto das pessoas -, que geralmente se seguia às apresentações do vídeo. Apesar disso, a equipe considerou um ganho o fato de propiciar a manifestação de dúvidas, receios e principalmente de rejeição aberta ao uso de fossas e ao controle de moluscos, expressa na única fala veemente de um senhor de certa idade.

Dezoito meses após os primeiros contatos do grupo com as comunidades, foi organizada, com apoio da Prefeitura Municipal, uma "Exposição sobre a esquistossomose", para prover as comunidades (principalmente da área onde trabalhávamos) com informações sobre a esquistossomose, consideradas necessárias para facilitar um processo de promoção da saúde. 
A "Exposição" consistiu em uma grande sala, com estandes contendo cartazes (sobre o ciclo, a prevenção, os sintomas, o diagnóstico e o controle da endemia), microscópios, monitor de vídeo, aquários, exemplares do molusco hospedeiro intermediário (Biomphalaria glabrata) e de um hospedeiro vertebrado não humano que participa do ciclo na região, complicando-o (Nectomys squamipes), e também ovos, larvas e casais do Schistosoma mansoni, o agente etiológico da esquistossomose. Havia, também, uma sala para exibição e discussão sobre o vídeo Doença do Caramujo e outra para atividades lúdicas, alusivas a aspectos diversos da esquistossomose, tais como jogos simples (dominó, memória, etc) e revista de passatempos.

Esta exposição contou com a presença de crianças, jovens, adultos e idosos residentes na nossa área de trabalho e dos dois funcionários aposentados que, nos anos 60, foram responsáveis pela "educação sanitária" no município, na qualidade de divulgadores sanitários.

A impressão positiva da experiência, durante a sua ocorrência, deveu-se a uma espécie de "sensação do dever cumprido". Entretanto, na sala de estandes, apesar dos muitos elogios recebidos, a participação da população foi passiva, praticamente não tendo sido externados questionamentos nem reflexões. As poucas reflexões críticas - sobre a utilidade ou não das fossas sépticas na área - reduziram-se a um pequeno grupo de adultos residentes na área em foco, presentes à sala de vídeo. $\mathrm{Na}$ sala de jogos, observamos que as atividades foram prazerosas e motivadoras.

Os resultados mais positivos desta exposição foram os seguintes: a) a constatação de que nas próximas experiências informativas, na sala de "estandes", deveria ser evitado o formato de "exposição", que pressupõe a existência de algo pronto, preparado por quem sabe, para quem não sabe, e 
que, por não saber, apenas assiste e se cala; b) a observação de que, sob a atenção da pesquisadora orientadora dos Grupos Focais, as sessões com o vídeo pareciam fluir melhor do que nas primeiras experiências, com utilização mais flexível do manual e criação de mais oportunidades de diálogo; c) a constatação de que a idéia de uma sala de jogos mostrou-se frutífera e digna de aperfeiçoamento para experiências posteriores; e d) a confirmação, principalmente com as sessões do vídeo, de que a população precisava ter acesso a mais informações sobre a esquistossomose, principalmente na região-alvo da intervenção.

Ao longo das diversas atividades realizadas nesta etapa, sobretudo através das sessões de vídeo, observamos a desesperança das pessoas alimentada por experiências passadas mal sucedidas e pela descrença no poder público. Passamos, também, finalmente, a entender que todos os que lidamos com comunidades, nesta perspectiva de intervenção em contextos ecossociais de doenças, temos responsabilidades como educadores. A partir deste entendimento, a maior preocupação da equipe passou a ser a de contribuir para a criação de condições para que se fizesse o diálogo entre a população, a equipe técnico-científica e a Prefeitura Municipal, abrindo caminho para a formação de uma "comunidade ampliada de pares", que pudesse atuar na busca de soluções para os problemas locais.

\subsection{Uma avaliação do trabalho}

Em junho de 1999, a equipe resolveu aplicar um questionário, para obter uma avaliação do trabalho até então desenvolvido junto à população. Além de identificar os respondentes por áreas (Pedreira, Porteira Verde Estufa, Santa Cecília e Pamparrão), sexo e idade, foram feitas perguntas sobre o que sabiam e gostariam de saber sobre o trabalho da equipe, se tinham participado do exame de fezes e do exame de sangue, se tinham recebido algum remédio, se haviam tomado o remédio, se alguma vez não o 
tomaram até o final e, no caso negativo, por que não haviam tomado. Perguntou-se, também, do que gostavam no trabalho e o que poderíamos fazer para melhorar o nosso trabalho. O questionário finalizava, perguntando se sabiam como nos encontrar, e se alguém ajudou a responder às perguntas.

Foram distribuídos 305 questionários, e preenchidos 239. Não nos é possível detalhar aqui, por limitação de espaço, os resultados encontrados. Vale dizer que os entrevistados mostraram-se, em sua maioria (57\%), informados sobre o trabalho realizado pela equipe. A avaliação positiva do trabalho é um aspecto a ser destacado, na medida em que se considere não ter sido demandado pela população. Por outro lado, é importante observar que, perguntados sobre o que gostariam de saber sobre o trabalho da equipe, 63 pessoas referiram-se especificamente ao que gostariam de saber (como são feitos os exames, as pesquisas, etc.), e um número razoável (29) manifestou a vontade de saber sobre a situação dos pesquisadores ou sobre a instituição.

Embora um bom número (49) de pessoas acreditasse que não era necessário melhorar nada, várias outras sugeriram que a equipe da Fiocruz estivesse mais presente (28), realizando campanhas de prevenção (9), tratando lagos e rios (12), realizando exames mais vezes, ou outros, de modo mais rápido (18). Algumas são formas suaves de apontar limitações. Há reivindicações, como o apoio dos governos municipal (3) e estadual (3), a criação de postos fixos de atendimento no local (7), e ter acompanhamento de um médico (5), indicando dificuldades de acesso ao sistema de saúde e a responsabilização das autoridades. Noutras respostas encontramos mais do que cobrança e apoio, a vontade de agir e de participar. É o que ressalta nas propostas de realizar encontros comunitários (2), incluir pessoas da região na equipe (3), e coletar mais informações dos moradores (1). 
Estamos diante dos resultados de uma avaliação de um trabalho de educação não-formal, realizado ao longo de três anos (1996-1999), com um envolvimento contínuo da equipe de pesquisa, e apresentação de resultados (exames) e divulgação científica (exposições/feiras), que ressaltam o respeito pelas pessoas e o interesse em estabelecer uma interação. $\mathrm{O}$ caráter sigiloso dos questionários abriu a possibilidade desta avaliação, que se mostrou uma verdadeira "pesquisa de opinião sobre o trabalho da Fiocruz", ao mesmo tempo em que projetava o interesse de uma parte dos moradores (ainda pequena, certamente) em criar um vínculo mais profundo com a equipe.

\subsection{Segunda exposição de saúde e ambiente}

Pouco depois da aplicação e discussão dos resultados do questionário, a equipe se mobilizou para dar corpo ao que denominou de "Feira de Saúde e Ambiente", em julho de 1999.

O comparecimento de crianças de várias escolas do município somente foi possível graças ao envolvimento direto do secretário municipal de educação, que requisitou a participação das professoras e disponibilizou o transporte para os estudantes. Nesta oportunidade participaram, além de equipe ampliada do IOC, duas antropólogas que atuaram como “observadoras externas".

A feira, organizada em quatro salas, foi dividida em circuito informativo, apresentação de vídeo, jogos e "bate-papo". A sala do circuito informativo trouxe os mesmos elementos da popularização científica sobre a esquistossomose da primeira exposição (1996), porém com o emprego de mais tecnologias. Três membros da equipe apresentam o ciclo da doença, o verme, sua reprodução, os problemas acarretados. Foi possível visualizar o 
verme no microscópio. Caramujos, com exemplares coletados na área de Sumidouro, foram apresentados num estande.

A preocupação dominante dos pesquisadores foi a de esclarecer a diferença entre o agente etiológico e o seu vetor e, ao mesmo tempo, apontar as condições que propiciavam a transmissão, bem como se fazia o tratamento dos doentes. Uma das pesquisadoras, por exemplo, sabendo que existia uma confusão entre o vetor e o verme, pergunta: $O$ que entra no corpo? É o caramujo? Uma criança balança, negativamente, a cabeça. Não. Interpreta o gesto, e aproveita para concluir: Então, agora vocês entenderam. Percebe-se, portanto, que o modelo pedagógico usado continuava a ser o mesmo de 1996: o sistema de pergunta-e-resposta, um sistema fechado, como se pode verificar nas respostas induzidas pelas perguntas (O que entra no corpo? É o caramujo?).

Alguns fatos merecem ser comentados: 1) segundo avaliação de alguns pesquisadores que participaram da sala de estandes, a atenção das pessoas, aparentemente, foi desviada das questões relativas à esquistossomose para os aparelhos e as coleções de espécimes apresentados nos estandes; 2) a equipe ficou decepcionada com a postura distanciada das professoras, que denotava enfado. Posteriormente, soube-se que estas haviam sido convocadas a acompanhar os alunos - o que não era comum nos fins de semana -, e que essa tarefa teria sido feita sem remuneração extra; 3) o vídeo e o questionário sigiloso foram instrumentos úteis à evidenciação de conflitos de interesses, com destaque para aqueles entre o conhecimento técnico científico e o conhecimento histórico das comunidades, como ocorreu, por exemplo, nas divergências sobre o uso de fossas; 4) nesta fase, principalmente nas discussões sobre os resultados do questionário sigiloso, observamos que, no caso de algumas pessoas, o pessimismo inicial, aos poucos, foi sendo substituído por uma espécie de "fé" em nós. Este fato foi 
identificado como um dos principais pontos para reflexão e revisão de atitudes da equipe, no sentido de estimulá-los na busca de soluções para seus próprios problemas; 5) observamos que não estavam maduras as condições para estabelecimento de uma comunidade ampliada de pares, nos moldes necessários ao enfrentamento dos problemas socioambientais locais, pois, apesar de haver uma relação de confiança, ligando a equipe técnicocientífica tanto ao poder público municipal como às comunidades, esses não se relacionavam bem entre si. Fato dos mais esclarecedores foi observado durante as eleições municipais de 1996, que se repetiu em 2000 e 2004: em Porteira Verde se reproduzia a polarização verificada no município, onde os principais grupos políticos se alternam no poder, eleitos com pouca diferença de votos.

\subsection{As necessidades de saúde da população e a questão da água}

Em 2000 terminou o tratamento das pessoas infectadas. Neste momento, o trabalho sofreu descontinuidade. De um lado, a eleição de um novo prefeito acarretou mudanças nas secretarias, pontos de apoio para o trabalho local da equipe da Fiocruz. Desafortunadamente, pelo lado da equipe, faltaram recursos para garantir a continuidade do trabalho.

Passam-se três anos. Neste meio tempo, a situação do município alterou-se, com melhorias na infra-estrutura urbana (transporte, rede de energia elétrica e de água). Ao retomar o contato, a equipe constatou também uma mobilidade sócio-espacial da população residente. Para a equipe de pesquisa, o maior problema, no tocante ao controle da esquistossomose, neste momento, estava representado pela situação de "apatia" da população - a propiciar a possibilidade de reincidência da doença. 
Apesar deste entendimento, o contexto da intervenção da equipe da Fiocruz, em 2003, já foi mais amplo. Assim, a feira de saúde e ambiente encaminhada em junho daquele ano, em outra localidade rural (Encanto), nunca antes trabalhada pela equipe, procurou dar conta de outras parasitoses e necessidades de saúde da população. Adotando, definitivamente, a prática de convidar observadores a participarem das atividades, nesta experiência de 2003, a equipe foi reforçada por duas cientistas sociais e por um agrônomo, nascido e criado em Sumidouro. Novas técnicas foram introduzidas para favorecer a participação dos moradores, a exemplo do “jogo do barbante”, para lidar com situações de sofrimento e compartilhar soluções, e a elaboração de representações sócio-espaciais da vida cotidiana, com a elaboração de "mapa" tecido em pano, numa nítida ruptura com o modelo de feira tradicional. Ao longo desta nova fase a questão da água torna-se relevante.

Em fins de 2004, quase cinco anos após a sua última visita à Porteira Verde, a equipe de pesquisa retornou a esta localidade, agora ampliada com a presença de um sociólogo, que já vinha dando suporte teórico ao grupo, tendo o objetivo de convidar os seus moradores e os do Pamparrão para discutirem a questão da água e outras "coisas boas e aquilo que a gente pode melhorar".

Precedida de convites feitos pessoalmente, de casa em casa, a reunião aconteceu numa escola pública por ser um lugar "neutro", dos pontos de vista político e religioso, o que, por si, era o resultado de uma reflexão sobre os moradores daquela localidade. Tal evento permitiu a emergência do problema da água em suas múltiplas dimensões.

Após o "jogo do barbante", no qual as palavras "amizade", "respeito" e "trabalho" deram o tom da participação, foi relatado o grande incômodo trazido por um abatedouro local, devido aos restos dos animais 
abatidos, focos de moscas espalhados pela área. E isso porque eram arrastados pelos cães que vagavam à noite, soltos. A Vigilância Sanitária nada fazia para responsabilizar o matadouro pela situação, que era mais grave no caso da poluição ambiental, posto que nem o gado de um curral, situado abaixo do matadouro, bebia a água dos despejos. Uma senhora lembrou que, há 40 ou 50 anos, a água do córrego podia ser bebida. O despejo dos dejetos dos animais nos córregos era motivo de outra sorte de dificuldades, nascida da vizinhança. De acordo com os moradores, o problema aqui era saber limpar, era dispor de fossas sépticas ou de esgoto sanitário. A rede de água canalizada e tratada não alcançava toda a população, principalmente porque alguns se recusavam a pagar a tarifa implicada na ligação à rede.

A sugestão da equipe, de realizar uma excursão fotográfica pelas proximidades, para, no dia seguinte, apresentar as fotos, abriu a possibilidade de esclarecimentos sobre os usos da água de fontes naturais e, ao mesmo tempo, apontou para o modo de exploração da terra pelos agricultores familiares. O uso de agrotóxicos, nas lavouras plantadas muito próximas das nascentes ou dos cursos de água, foi uma das questões levantadas por um dos participantes. Neste contexto, surgiu a proposta de organizar uma associação de moradores da localidade.

A tentativa da criação de uma associação de moradores em Porteira Verde aconteceu meses depois, expressando o embrião de uma liderança local. Não se chegou a um bom termo, porém, por causa da divisão entre moradores e produtores. A esta divisão se sobrepôs uma clivagem de gênero, na medida em que as mulheres foram excluídas da organização da associação de produtores. Já não bastasse este motivo para causar indignação e revolta, havia acusações de que os proponentes da associação 
de produtores teriam vínculos com um vereador da legenda partidária derrotada nas eleições municipais.

Para os pesquisadores, a situação era bastante delicada, posto seu interesse em envolver o conjunto dos interessados em encaminhar coletivamente a "questão da água", isto é, a agenda de reivindicações dos moradores da localidade. A explicitação das diferenças de interesse, ao longo da assembléia, constituiu, para nós, um aprendizado sobre a complexidade de interesses a envolver uma população, aparentemente homogênea, do ponto de vista social.

\section{Discussão e considerações finais}

A partir de 2003, uma postura autocrítica compeliu os pesquisadores a buscarem apoio em novas leituras - sobretudo na obra de Paulo Freire - e na prática de colegas com formação em Ciências Sociais.

Este suporte nos mostrou que o ponto de partida da interação do pesquisador, geralmente, é a história anterior da pesquisa, isto é, a caracterização da área como endêmica e as representações sobre a população, construídas por outros pesquisadores, ou seja, pelo conhecimento científico acumulado. No caso de Sumidouro, este conhecimento é principalmente biológico e de saúde pública, acompanhado de informações baseadas nas experiências dos pesquisadores e em dados censitários. Tal conhecimento é, inevitavelmente, reducionista, porque expressa o desconhecimento da complexidade das relações e da dinâmica sociais da população que será alvo de uma intervenção sanitária. A interação entre pesquisadores e moradores é uma relação sócio-cultural, caracterizada, inicialmente, pelo desconhecimento mútuo das lógicas comportamentais (FREUDENBERG, 1985), inclusive em decorrência de determinações mais 
estruturais, que implicam, em nossa sociedade, a superioridade da cidade sobre o campo.

O risco dos pré-conceitos se naturalizarem foi atenuado pelas dificuldades da interação e pelo desejo de superá-las - o que não aconteceu nas intervenções sanitárias anteriores a 1990. No processo mais recente, o respeito e a busca de entendimento das razões das dificuldades de interação tiveram importância na superação da intervenção autoritária, típica das décadas de 1960 a 1980. Obviamente, vivíamos noutro contexto, o da democratização das relações entre sociedade e estado.

Outro aspecto a considerar diz respeito ao fato do saber escolarizado orientar o trabalho educativo com uma população predominantemente não escolarizada. Nesta perspectiva, vale tomar como exemplo o sistema de perguntas e respostas fechadas, método que não contempla o contexto sóciocultural; simplesmente transpõe um procedimento de escolarização para uma população não escolarizada (dificuldade de ler material escrito, dificuldade de expressão - linguagem "abstrata", quer dizer, separada da vida, saber "escolástico"). É o saber técnico, lançando mão da escolaridade como parâmetro de competência para aprender, desqualificando o saber popular (FREIRE, 1971, VALLA, 1993). São pressupostos e métodos característicos da educação bancária, ainda que bem intencionada. No trabalho realizado entre os anos 1995-2004, a ruptura com este modelo foi parcial, pois resultou, principalmente, das dificuldades em atingir os objetivos, e não de uma crítica, e superação deste por outro modelo; mas foi uma ruptura progressiva, como se constata na experiência do convívio (OLIVEIRA; STOTZ, 2004), com ganhos em termos de comunicação, adesão e proposição de alternativas próprias.

O processo de nossa aprendizagem com agricultores desenrolou-se, durante um bom tempo, em meio a uma situação constrangedora de silêncio 
e apatia. O sentimento, daí decorrente, de que alguma coisa "faltava" ao saber especializado, provocou diversas respostas, desde a incorporação de cientistas sociais na equipe até a aplicação de instrumentos e técnicas para aproximar a população. Tais respostas, contudo, circunscreviam-se dentro dos limites da própria consciência ingênua dos pesquisadores. Não entrava em cogitação a própria intervenção educativa, como parte intrínseca da política pública destinada ao controle social das populações, expresso no objetivo de mudar comportamentos e hábitos mediante a disseminação de informações.

Certamente, a aplicação do questionário sigiloso, o uso mais flexível dos vídeos e a introdução de formas mais participativas nas exposições científicas permitiram maior aproximação entre a equipe e a população. Mas foram respostas a problemas postos pela equipe e não pela população. Ademais, a equipe não percebeu, desde o início, a implicação de sua intervenção educativa na hierarquia social de um município pequeno, predominantemente rural, com grande índice de analfabetismo. Foi aprendendo, na medida da própria ampliação do trabalho educativo e da secundarização do saber especializado, que a apatia e o silêncio, constatados ao longo das intervenções, podem ter diferentes significados, de acordo com a psicologia social do campesinato, o contexto de vida e o grau de envolvimento dos pesquisadores no âmbito local.

Como a experiência de Sumidouro permite inferir, grupos sociais explorados ou oprimidos procuram transformar o envolvimento da equipe de pesquisadores científicos em verdadeiros pontos de apoio para seus próprios objetivos e interesses. Ora, isto implicaria dar à pesquisa outros sentidos e usos. Daí a importância do exercício da "escuta ativa e metódica", proposta por Bourdieu (2001): colocar-se, inicialmente, no lugar das pessoas, no pensamento, isto é, tentar entender o processo no qual elas 
estão envolvidas, a sua posição, as dificuldades e as possibilidades, para, então, com a participação delas próprias, ajudar a desvendar outros caminhos. Porque a história não começa com a entrada dos pesquisadores em campo. Nós nos dedicamos a fazer este exercício a partir de 2003, mas é sintomático que apenas o tenhamos iniciado, quando concluímos o tratamento das pessoas infectadas.

\section{Referências bibliográficas}

BERLINGUER, Giovanni (1988). A doença. São Paulo: Hucitec.

BOURDIEU, Pierre (2001). Compreender. In: BOURDIEU, Pierre (Coord.) A miséria do mundo. Petrópolis: Vozes.

BOURDIEU, Pierre; CHAMBERON, Jean-Claude; PASSERON, JeanClaude (1999). A profissão do sociólogo: preliminares epistemológicos. Petrópolis: Vozes.

FREIRE, Paulo (1971). Extensão ou Comunicação? Rio de Janeiro: Paz e Terra.

FREUDENBERG, N. (1984-85). Training health educators for social change. International Quarterly of Community Health Education, v. 5, n. 1.

FUNTOWICZ, Silvio; RAVETZ, Jerry (1997). Ciência pós-normal e comunidades ampliadas de pares face aos desafios ambientais. Revista História, Ciências, Saúde, v. 4, n. 2, p 219-230.

OLIVEIRA, Maria Waldenez; STOTZ, Eduardo Navarro (2004). Perspectivas de diálogo no encontro entre organizações não governamentais e instituição acadêmica: o convívio metodológico. In: REUNIÃO DA ASSOCIAÇÃO NACIONAL DE PÓS-GRADUAÇÃO E PESQUISA EM EDUCAÇÃ̃O, 27, 2004, Caxambú - MG, Anais... (Temática: Sociedade, Democracia e Educação: qual Universidade? GT - Educação Popular). CD ROM. ISBN 85-86392-12-X.

OLIVEIRA, Roberto Cardoso de (2000). O trabalho do antropólogo. São Paulo: UNESP.

SILVA, Marcos Diniz da (2004). Memória da esquistossomose no município de Sumidouro, RJ, Brasil. Monografia de conclusão do 
Programa de Vocação Científica da Escola Politécnica de Saúde Joaquim Venâncio com o CIEP 326 Prof. César Pernetta, orientado por Marisa da Silveira Soares e Marli B. M. de Albuquerque Navarro. Rio de Janeiro: Fundação Oswaldo Cruz.

SOARES, Maria da Silveira et al. (1998). Solução de problemas em saúde e ambiente: ciência pós-normal e comunidade ampliada de pares em um município brasileiro de pequeno porte. Ciência \& Saúde Coletiva, v. 3, n. 2, p. 115-123.

SOARES, Maria da Silveira; STOTZ, Eduardo Navarro; BARRETO, Magali Gonçalves Muniz (2005). A questão da água em área rural: relato de uma experiência sobre o aprendizado dos cientistas com agricultores familiares. In: V COLÓQUIO INTERNACIONAL PAULO FREIRE, 2005. Recife: Centro de Estudos Paulo Freire - Estudos e Pesquisas, Livro de Resumos do V Colóquio Internacional Paulo Freire, v. 1, p.139-140.

VALLA, Victor Vincent (1993). A construção desigual do conhecimento e o controle social dos serviços públicos de educação e saúde. In: VALLA, Victor Vincent; STOTZ, Eduardo Navarro (Orgs.). Participação popular, educação e saúde: teoria e prática. Rio de Janeiro: Relume-Dumará.

\section{Autores}

\section{Eduardo Navarro Stotz}

Departamento de Endemias Samuel Pessoa/Escola Nacional de Saúde Pública/Fundação Oswaldo Cruz

Praia de Botafogo, 114/503 - Rio de Janeiro - RJ - 22250-040

stotz@ensp.fiocruz.br

\section{Marisa da Silveira Soares}

Laboratório de Avaliação e Promoção da Saúde Ambiental/Instituto Oswaldo Cruz/Fundação Oswaldo Cruz

mssoares@ioc.fiocruz.br

\section{Magali Gonçalves Muniz Barreto}

Laboratório de Avaliação e Promoção da Saúde Ambiental/Instituto Oswaldo Cruz/ Fundação Oswaldo Cruz

mbarreto@ioc.fiocruz.br 


\section{Como citar este artigo:}

STOTZ, Eduardo Navarro; SOARES, Marisa da Silveira e BARRETO, Magali Gonçalves Muniz. Aprendizagem de pesquisadores científicos com agricultores: reflexões sobre uma prática em Sumidouro $(\mathbf{R J})$, Brasil. Revista ACOALFAplp: Acolhendo a Alfabetização nos Países de Língua portuguesa, São Paulo, ano 1, n. 1, 2006. Disponível em: <http://www.acoalfaplp.net>. Publicado em: setembro de 2006.

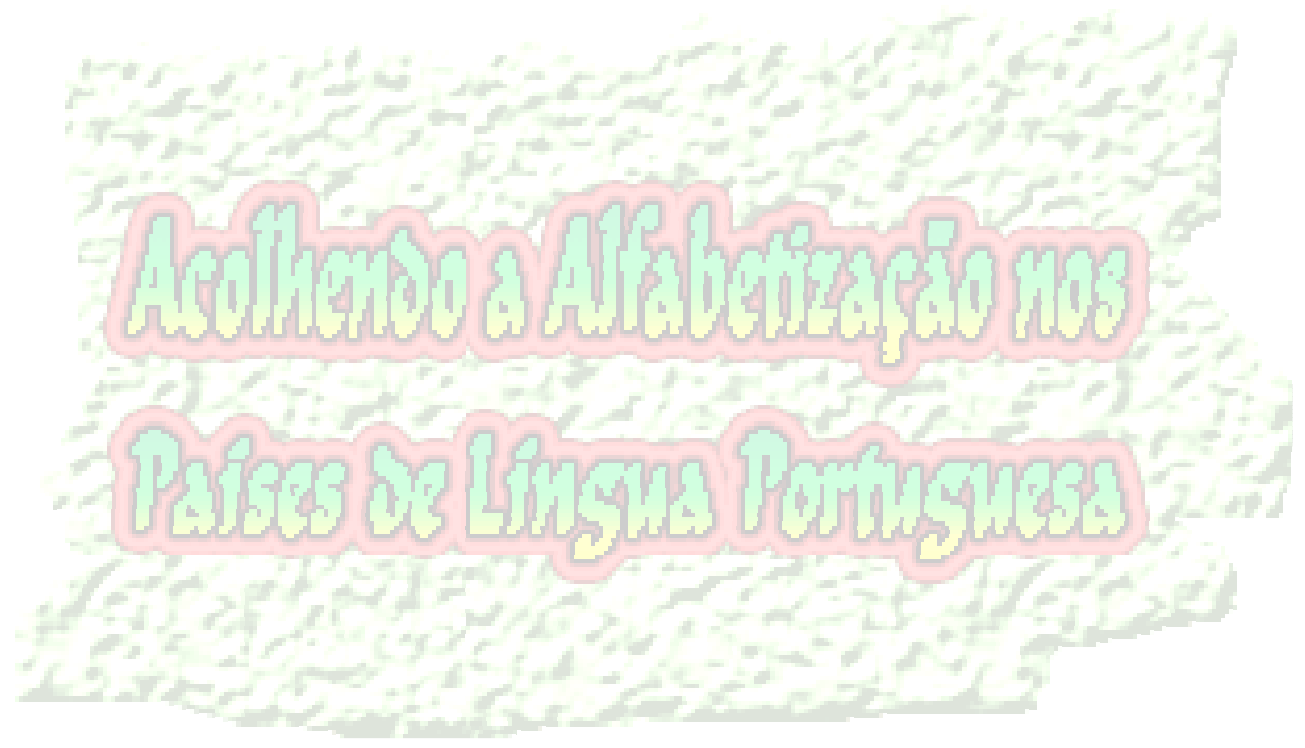

